\title{
Gobierno de las leyes y/o gobierno de los ciudadanos. ¿Hay compatibilidad entre republicanismo y democracia liberal? ${ }^{1}$
}

\author{
Alessandro PinZani \\ UFSC, Florianópolis
}

RESUMEN. Este ensayo se ocupa de discutir el renacimiento de la tradición republicana en los últimos años, particularmente gracias a pensadores como Quentin Skinner, Maurizio Viroli y Philip Pettit. Se aborda esta tradición en sus principales elementos constitutivos, a saber: 1) el concepto de república propiamente dicho; 2) el papel central de las virtudes cívicas; 3) la concepción republicana de libertad; y 4) el concepto de gobierno de las leyes. Se desarrolla, en primer lugar, un breve análisis de estos cuatros elementos, al mismo tiempo que se ponen en evidencia algunos problemas históricos y teóricos. A continuación, se compara la posición de los teóricos republicanos, tanto clásicos como contemporáneos, con la propia de la tradición liberal-democrática, que, para aquéllos, constituye el principal blanco de esta polémica. Finalmente, se introduce una nueva corriente de pensamiento que los neo-republicanos dejan, curiosamente, de lado: el constitucionalismo.

Palabras clave: republicanismo, liberalismo, democracia, constitucionalismo, virtudes cívicas, gobierno de las leyes.
ABstract. The paper aims to discuss the renaissance of the republican tradition in the last years - particularly thanks to authors like Quentin Skinner, Maurizio Viroli and Philip Pettit. The paper takes into account the main elements of this tradition, i.e.: (1) the concept of republic itself, (2) the central role of civic virtues, (3) the republican concept of liberty, (4) the idea of the rule of law. Firstly, these four elements will be shortly analyzed, while some historical and theoretical problems will be emphasized. Then, the position of republican authors (both classical and contemporary ones) will be compared to the liberal-democratic tradition, which constitutes the main aim of their critics. Finally, a further tradition (that neorepublicans leave - curiously enoughaside) will be introduced: constitutionalism.

Keywords: republicanism, liberalism, democracy, constitucionalism, civic virtues, government of the law.

\footnotetext{
${ }^{1}$ Este ensayo es una versión reelaborada y ampliada de un artículo publicado en los Annali del Dipartimento di Filosofia dell' Università degli Studi di Firenze, 2005, pp. 299-315. Agradezco a Leandro Cisneiros por su ayuda en la traducción al castellano.
} 


\section{El descubrimiento de una tradición «olvidada»}

El célebre jurista alemán Ernst-Wolfgang Böckenförde formuló hace algunos años un diagnóstico bastante drástico sobre la supervivencia de nuestras democracias contemporáneas. En su opinión, el Estado liberal que resultó del proceso de secularización se sostiene sobre presupuestos que él mismo no es capaz de garantizar (Böckenförde, 1991, 112) y, por tanto, si pretende sobrevivir, debe buscar nuevas energías vitales en otra parte, por ejemplo, en una determinada actitud de los ciudadanos, además de en las propias instituciones. En Alemania, este diagnóstico se tornó un lugar común en los debates políticos y filosófico-políticos. De todos modos, no es sólo Böckenförde quien insiste en destacar la necesidad de que el Estado liberal se haga cargo de la presencia de un cierto ethos público, de una cierta conciencia cívica entre sus ciudadanos. El tema de la moralidad civil o de las virtudes cívicas no es particularmente nuevo en la historia del pensamiento político, más bien, todo lo contrario. De cualquier manera, esta cuestión está experimentando, sin duda alguna, un renacimiento en los últimos años. Más allá de constituir un importante elemento de contraposición en el debate entre liberales y comunitaristas, debate que se arrastra desde hace muchos años y que ya pareciera estar superado, el tema de la moralidad civil está volviendo con fuerza a un primer plano, dentro del contexto del nuevo gran choque «ideológico» que está dominando la escena de la filosofía política contemporánea: aquel que enfrenta al republicanismo y el liberalismo o, mejor dicho, entre teóricos neo-republicanos y liberales.

Los neo-republicanos se remiten a una tradición que habría perdido visibilidad en los últimos dos siglos, aunque ello no implica que hubiera desaparecido completamente. Como ocurre con algunos ríos, esta tradición debe haber continuado su curso por canales subterráneos, dominada por grandes ideologías, como es la liberal, la socialista y —en el siglo veinte - la fascista, para, finalmente, emerger de nuevo y proponerse como tercera vía. Tercera vía entre liberalismo y comunitarismo, según lo afirma Quentin Skinner en 1984, o sea, cuando el debate entre estos dos «ismos» estaba en pleno auge; o, también, tercera vía entre pensamiento liberal y pensamiento radical-democrático, según afirma hoy Maurizio Viroli.

En realidad, esta apelación al republicanismo no constituye absolutamente una novedad en el pensamiento del siglo veinte. Arendt ya había «redescubierto» una tradición alternativa, no solamente a la liberal, sino también a toda la filosofía política desde Platón: la tradición de la polis (Arendt, 1958). Después, en la mitad de los años setenta, aparece el libro de Pocock sobre la influencia de Maquiavelo en el pensamiento político anglosajón, libro que, como lo reconocen los mismos neo-republicanos, marca un vuelco en el renacimiento de la tradición republicana (Pocock, 1975), y las primeras investigaciones de Bellah sobre el papel de la religión en la vida política 
norteamericana (Bellah, 1975) —un tema en boga entre los pensadores republicanos clásicos- Finalmente, también podríamos mencionar el libro de Hans Baron sobre el humanismo cívico de 1955, que, de todos modos, parece haber tenido una influencia sólo marginal en el debate actual, aun cuando constituya una etapa fundamental para la actual definición de la tradición republicana y de los conceptos de ella.

A partir de ello, en este contexto, me ocuparé de las posiciones de los pensadores neo-republicanos de tradición anglosajona, ya que es de ellos de donde nos llegan las contribuciones más importantes para el debate con la tradición liberal. Concentraré mi atención, particularmente, sobre tres autores: Quentin Skinner, Philipp Pettit y Maurizio Viroli, a quienes, de alguna manera, podríamos llamar «escuela de Princeton», pues todos estos pensadores estuvieron vinculados o, todavía lo están, a esta célebre universidad norteamericana (Pettit, 1997; Skinner, 1998; Viroli, 1999).

No es mi intención hacer una crítica exhaustiva a la posición de estos tres pensadores. Sólo me limitaré a un aspecto de esta posición: a la idea de que la tradición republicana se contrapone, de manera irreconciliable, a la tradición liberal y a una determinada concepción de democracia. Este recorte de mi objeto de análisis también acarrea una dificultad que no es menor, a saber: ofrecer una definición satisfactoria de los conceptos de liberalismo y de democracia, naturalmente, más allá del de republicanismo. De cualquier manera, en este sentido, nuestros tres autores pueden ayudarnos.

\section{El árbol genealógico republicano}

El punto de partida de ellos, particularmente el de Skinner en su libro titulado, programáticamente, Liberty Before Liberalism (1998), consiste en demostrar la existencia de una tradición política alternativa al liberalismo, como ya lo dije anteriormente. Skinner entiende que puede encontrarla en la Italia del Renacimiento y, sobre todo, en la Inglaterra entre los años 1630 a 1688 , o sea, antes que Hobbes y Locke aportasen las primeras formulaciones del liberalismo clásico (respectivamente en De Cive, de 1642, y en el Segundo tratado sobre el gobierno, de 1689). Para denominar estos autores anglosajones del siglo XVII, Skinner prefiere la expresión «new Roman theorists» (Skinner, 1998, pp. $10 \mathrm{~s}$.), pues no todos ellos promovieron la abolición de la monarquía, por tanto, no todos fueron republicanos en sentido estricto. Viroli, por el contrario, entiende que pueden encontrarse las raíces de lo que él llama árbol genealógico republicano, en una época más remota, partiendo de Cicerón, Tito Livio y Salustio, de los cuales sólo el primero puede ser considerado un filósofo, además de un orador y hombre político. En este árbol genealógico encontramos algunos teóricos medievales, principalmente, autores de tratados y manuales para gobernantes, y hasta un artista plásti- 
co como es el pintor Ambrogio Lorenzetti, por los frescos alegóricos pintados por él en el Palacio Público de Siena (Riklin, 1999). Después, encontramos los humanistas florentinos: Salutati, Bruni, Palmieri, Rinuccini, Maquiavelo y Giannotti, quienes ocuparon cargos públicos, además de escribir sobre política. Después llegamos a los «new Roman theorists» ingleses: Francis Bacon, Ben Johnson, James Harrington, John Milton, Algernon Sydney, Lord Bolingbroke y Jonathan Price, un contemporáneo de Kant. Finalmente, llegamos a la cumbre con Rousseau y los Founding Fathers norteamericanos, particularmente Hamilton, Madison y Jay (autores de los Federalist Papers), o el adversario de ellos, George Clinton. A partir de este punto, parece abrirse un verdadero abismo, en el cual el pensamiento republicano desaparece, para volver a emerger de nuevo en nuestros días (Viroli, 1998, siglo XIII ; también Honohan, 2002; Skinner y Van Gelderen, 2002).

Llama la atención que ni Skinner ni los otros neo-republicanos ofrezcan una definición histórica o teórica, igualmente precisa, de la tradición liberal criticada por ellos. Ellos mencionan a Locke, Constant o John Stuart Mill, pero no mencionan a varios pensadores modernos que, normalmente, son considerados liberales. En su libro Republicanism, Pettit cita a Kant sólo una vez, para definirlo como un «continental romantic» (!) como Herder, Rousseau, Fichte, Hegel y Marx (Pettit, 1997, p. 18); hasta Locke, él intenta reclutar entre los republicanos, en este libro. En general, pensadores liberales contemporáneos como Rawls, Dworkin o Nozick, no son ni siquiera mencionados, como si las únicas fuentes de polémica de los neo-republicanos sólo se encontraran en épocas pasadas.

Dejando de lado esta peculiaridad, podemos resumir la tradición republicana en los siguientes elementos constitutivos: 1) el concepto de república propiamente dicho; 2) el papel central de las virtudes cívicas; 3) la concepción republicana de libertad; 4) el concepto de gobierno de las leyes.

Primeramente, desarrollaré un breve análisis de estos cuatros elementos, al mismo tiempo que dejo en evidencia algunos problemas históricos y teóricos. A continuación, comparo la posición de los teóricos republicanos (clásicos y contemporáneos) con la posición de aquella tradición liberal-democrática, que, para ellos, constituye el principal blanco de esta polémica. Finalmente, introduciré una nueva corriente de pensamiento que los neorepublicanos dejan, curiosamente, de lado: el constitucionalismo. Por esta razón, me concentraré, principalmente, en la definición de libertad ofrecida por los neo-republicanos y en el concepto de gobierno de las leyes, dando menos atención a los otros dos puntos, a saber: república y virtudes cívicas, que, por su parte, merecerían ser profundizados por separado. A pesar de ello, iniciaré mi análisis, justamente, a partir de estos dos puntos. 


\section{El concepto de república y las virtudes cívicas}

1) En la concepción republicana, una república es una comunidad basada en el Derecho y en el bien común. Cicerón escribe en De re publica que res publica significa, justamente, la cosa del pueblo, definido este último como la reunión de individuos asociados por medio de un acuerdo concerniente a ciertas obligaciones jurídicas y a la busca del interés común (I, 25). Ninguno de los sucesivos pensadores republicanos verá necesario incrementar nada a esta definición. Rousseau, por ejemplo, escribe en el Contrato social (libro II, cap. 6): «Llamo, pues, república a todo Estado regido por leyes, bajo cualquier tipo de administración que pueda hallarse; porque entonces solamente gobierna el interés público y la cosa pública [la choise publique, o sea, la res publica latina - A.P.] pasa a representar algo» (Rousseau, 1996, p. 38).

La exigencia imperativa de que las leyes den cuenta del bien común es un topos de la tradición republicana, que, lamentablemente, la mayoría de las veces, es genérica, por faltar una definición unívoca del propio bien común. Pues, me parece que ninguno de los representantes clásicos del republicanismo ha conseguido ofrecer una definición convincente en este sentido. En la mayoría de los casos, ellos se limitan a una definición mínima, como aquella según la cual el sumo bien de la república consistiría en la salvaguarda de la propia independencia política; pero también en este caso, como veremos a continuación, quedan problemas abiertos.

Todos los teóricos neo-republicanos (incluidos los pensadores que se inspiran menos en la tradición del humanismo cívico, como Benjamín Barber [Barber, 1984]), insisten en la importancia de la participación de los ciudadanos en la vida política del Estado: otro tema típico del republicanismo clásico. Hay una tensión entre esta exigencia y el hecho de buscar inspiración en la polis griega, en la Roma republicana, en las repúblicas renacentistas de Florencia y Venecia y en los Estados Unidos de los Founding Fathers (dejo de lado la cuestión, sin duda interesante, acerca de ¿en qué medida no se trata de modelos fuertemente idealizados?, particularmente en el caso de los EEUU: Madison y los otros se «enmascaran» de antiguos romanos - hasta en la elección de sus seudónimos-, pero utilizan argumentos extraídos de pensadores liberales, como Locke y Hume). En todas estas repúblicas, la participación política era limitada a pocas personas. Ciudadanos, en el sentido más propio del término (o sea, ciudadanos que contribuían efectivamente al proceso legislativo y no eran simplemente ciudadanos «pasivos» - para usar la expresión kantiana-), eran solamente los propietarios de tierras o profesionales liberales, de sexo masculino, mientras mujeres y esclavos (cuando había) eran siempre excluidos. En algunos casos había ulteriores restricciones, ligadas al estatus social (como en Venecia, donde solamente 
los miembros de algunas familias podían participar de la vida política); a la situación económica (como en los EEUU, donde trabajadores asalariados, hasta 1824, fueron discriminados para cubrir cargos públicos) o, inclusive, a contingencias geográficas (solamente personas nacidas en Atenas podían ser ciudadanos; solamente los habitantes de Florencia y no los de los dominios florentinos podían participar de la vida política de la ciudad). Finalmente, la mayoría de estas republicas, que defendían ferozmente su libertad, no tenían el menor respeto para con la libertad de los otros Estados. Ellas no amaban la libertad en sí, sino sólo su propia libertad (véase, por ejemplo, el expansionismo imperialista de la Atenas de Pericles, de Roma o de Venecia; la inexorable explotación que Florencia imponía al contado; y -last but not least_la doctrina Monroe).

Por supuesto, éstos no son argumentos contra la concepción republicana en sí; pero ellos nos ayudan a entender una de sus características centrales, sobre la que los neo-republicanos prefieren callar: la idea de que solamente algunos individuos deberían decidir lo que es bueno para el Estado. El problema no es solamente que todas estas repúblicas se fundaban a partir del dominio de una minoría sobre una mayoría; sino que los autores clásicos, que las señalan como modelos que deberían ser imitados, no cuestionan este dominio ni la exclusión de grupos significativos de individuos (mujeres, esclavos, asalariados, negros, no-aristocráticos, habitantes de territorios periféricos, etc.) fuera de la vida política. Muchos de estos autores (como, por ejemplo, Rousseau, y muchos Founding Fathers, como Washington, Madison o John Adams) pensaban, además, que «el pueblo» (o sea: los varones libres y adultos) no era capaz de identificar el bien común y, por tanto, de legislar. Ellos pensaban que el único papel del pueblo era el de elegir sus representantes (quienes, por definición, tenían una mejor visión del bien común), o el de ratificar las decisiones y las leyes del gobierno. La asamblea pública descrita por Rousseau, por ejemplo, no es una asamblea legislativa en el sentido que hoy atribuimos a este término: su tarea era simplemente la de aceptar o rechazar las leyes propuestas por los magistrados (o sea, por el gobierno). La misma desconfianza se encuentra en pensadores, tan lejanos entre sí, como Cicerón y Harrington, pero también puede ser observada en el debate acerca de la Constitución norteamericana (Schudson, 1999).

2) Con respecto al segundo punto, los teóricos republicanos entienden que ninguna república puede mantenerse por mucho tiempo, si sus ciudadanos no desarrollan determinadas virtudes cívicas. También sobre la definición de estas virtudes, las opiniones son divergentes. Pero, a pesar de ello, hay un cierto acuerdo, por lo menos, sobre una de ellas: la capacidad de los ciudadanos de sacrificar sus intereses para el bien común. Esto nos remite nuevamente a la cuestión de la definición de este bien —cuestión sobre la cual, como ya dije, volveré más tarde-. 
En lo que respecta a las otras virtudes, el listado es, frecuentemente, muy diferente, según el pensador de que se trate, e incluye actitudes o cualidades del carácter, que no siempre son fáciles de definir, como, por ejemplo, el amor a la patria. De todos modos, en general, prevalecen las virtudes «belicosas», como el patriotismo, el coraje, el valor militar, la abnegación, la disciplina. Una consecuencia de estas virtudes, y de la idea de que el bien común es el sumo bien, que debería inspirar todo acto de los ciudadanos particulares, es una cierta radicalización del disenso político.

Un patriota que está convencido de estar persiguiendo el bien común del país, tenderá a ver, inevitablemente, sus adversarios políticos como individuos ciegos e incapaces de percibir la verdad, o como enemigos de la patria, o ambas cosas a la vez - como eficazmente lo narra Saramago en su más reciente novela, Ensayo sobre la lucidez (Saramago, 2004)-. Así, simples conflictos de intereses y de opinión se tornan conflictos ideológicos sobre la «verdadera» naturaleza de la comunidad y de sus intereses, como también lo reconoce un defensor del ideal de las virtudes cívicas, Michael Walzer (Walzer, 1996, p. 189). De este modo, posiciones divergentes de la de uno, serían consideradas no solamente como posiciones, justamente, adversas, sino como posiciones falsas y perniciosas. Pasar de una actitud política de este tipo, hacia una abierta discriminación contra el adversario político es muy fácil y, más fácil lo es todavía, el paso de esta discriminación al uso de la fuerza. No es por casualidad que los terroristas políticos y los golpistas se presentan, en todos los tiempos, como «salvadores de la patria» (cfr. Pinzani, 2004).

En lo que respecta a las virtudes menos militares, como, por ejemplo: la solidaridad entre los conciudadanos; el respeto por las leyes, aun cuando el castigo por infringirlas sea improbable; el respeto por los diversos estilos y modos de vida, diferentes de los de uno; la tolerancia religiosa; la disponibilidad para el diálogo, etc.; no me parece que el republicanismo se diferencia mucho del liberalismo. Antes de proseguir, me gustaría señalar el hecho de que la mayoría de los teóricos liberales creen que una sociedad liberal puede sobrevivir sólo si los miembros poseen determinadas cualidades que, algunos llegan, incluso, a llamar «virtudes liberales». Estoy pensando en autores contemporáneos, como Stephen Macedo, William Galston, Richard Dagger, David Strauss, Stephen Holmes (Macedo, 1990 y 1992; Galston, 1991; Strauss, 1992; Holmes, 1993; Dagger, 1997), pero también en el mismo Rawls (ya sea en A Theory of Justice, o en Political Liberalism [Rawls, 1971 y 1993]) — sin hablar de pensadores clásicos como el Locke de los Pensamientos sobre la educación, John Stuart Mill o el propio Kant (y sin considerar el hecho de que el mismo Hobbes afirma que para la sobrevivencia del Leviatán es necesario que los ciudadanos desarrollen virtudes como la moderación, la justicia, la disponibilidad para perdonar, etc.)-. 


\section{Libertad republicana contra libertad liberal y libertad democrática}

3) Llegamos al tercero y decisivo de los puntos, aquel que nos dice respecto de la definición de libertad. Según los republicanos, la verdadera libertad consistiría en la independencia del arbitrio de otros, y presupondría la igualdad de los ciudadanos ante la ley. Esta independencia vale, en primer lugar, para el Estado. Según la célebre fórmula de Bartolo de Saxoferrato, la cual representa, tal vez, la más longeva formulación del concepto de soberanía política, libre es la ciudad que no reconoce algún poder superior («potestas superiorem non recognoscens»). Por tanto, libre es la ciudad que sabe autogobernarse. En este sentido, los municipios y las ciudades-repúblicas de la Italia medieval o del Renacimiento constituyem, según los neo-republicanos, un excelente ejemplo de libertad republicana. Estas ciudades (a pesar de las desigualdades sociales internas, a pesar de las tendencias oligárquicas siempre latentes entre ciertos sectores de la población, y a pesar de la derrota final ante la superioridad de potencias extranjeras, organizadas en Estados-naciones con gobiernos absolutistas) encarnaron durante mucho tiempo el principio del autogobierno cívico y tradujeron en la praxis política el principio clásico de un gobierno de las leyes y de las instituciones, opuesto al gobierno personalista de los príncipes y de los monarcas absolutos que reinaban en otros lugares.

Además, la libertad republicana es confrontada, por los neo-republicanos, con la liberal y la democrática. Por un lado, con respecto a la tradicional distinción entre libertad de los antiguos y libertad de los modernos, hecha por Constant (Constant, 1819), y, por otro lado, con respecto a la distinción, también tradicional, entre libertad negativa y positiva elaborada por Isaiah Berlin (Berlin, 1969), Pettit distingue entre: la libertad negativa como no-interferencia, propuesta por los liberales; la libertad positiva como autogobierno de las teorías democráticas y la libertad como independencia de los republicanos (Pettit, 1997).

En esta lectura, para los liberales, la libertad solamente sería la libertad de la cual gozan los individuos, al verse librados de cualquier interferencia en sus acciones. Pero, viendo que la convivencia humana necesita reglas, como lo muestra el experimento mental del estado de naturaleza, y visto que cada sistema de leyes representa una interferencia en la libertad individual, no es posible alcanzar una libertad absoluta - como querían algunos libertarios extremos o anarquistas - y la mayor preocupación de los liberales sería aquella de reducir esta interferencia a un nivel mínimo (como lo quería Locke), o aquella de hacerla lo más eficaz posible, independientemente de su amplitud, como - en la lectura de Pettit y de Viroli- lo quería Hobbes. Desde este punto de vista, entonces, el liberalismo sería compatible con cualquier forma de gobierno, inclusive con un gobierno despótico. Según 
Viroli, al contrario, ningún republicano llamaría libertad a la presunta libertad concedida magnánimamente por un déspota «liberal», que permita, por un lado, a los súbditos hacer lo que ellos quieran, pero que, por otro lado, en cualquier momento pueda privarlos de este permiso (Viroli, 1999, p. 25).

La diferencia entre interferencia y dominación merece ser profundizada brevemente, ya que se trata de un punto central en lo que respecta a la distinción entre liberalismo y republicanismo. Según Pettit, la interferencia implica una restricción intencional de las opciones de elección de alguien, con lo cual lo que la caracteriza negativamente es solamente su eventual arbitrariedad (Pettit, 1997, p. 272). Por otro lado, también puede haber dominación cuando no haya una concreta interferencia, como en el caso mencionado arriba, el déspota liberal que deja sus súbditos libres, sólo en la medida en que él quiere. El mero riesgo de una interferencia arbitraria, o sea, la presencia de una interferencia potencial o virtual, nos permite hablar de una dominación. En seguida volveré sobre este asunto.

Los neo-republicanos también rechazan el concepto positivo de libertad, entendido como autonomía o autogobierno, el que constituye una idea típicamente democrática. Viroli y los otros definen democracia como la forma de gobierno en la cual el poder de decisión es ejercido por la totalidad, o la mayoría de los ciudadanos. Por tanto, hay en ellas, un gobierno de los hombres y no de las leyes (Viroli, 1999, p. 32), entonces cada ley, aun cuando sea creada democráticamente, es arbitraria: «Una ley, aceptada voluntariamente por los miembros de la más democrática de las asambleas, puede igualmente ser una ley arbitraria, que permite que algunos fuercen la voluntad de otros y, por ello, priven a estos últimos de su autonomía» (Viroli, 1999, p. 27).

La concepción republicana, al contrario, no identifica la libertad con la autonomía o con el autogobierno, y se fundamenta en el gobierno de las leyes y no de los hombres ${ }^{2}$. Citando a Rousseau, Viroli afirma que la voluntad es autónoma, cuando es protegida de la amenaza persistente de asumir una imposición externa, pero no cuando las leyes o normas que determinan mi conducta son el resultado de un acto de mi propia voluntad. La autonomía, entendida como la facultad de darse leyes, es sólo un instrumento para vivir libremente; de todos modos, para Viroli, lo decisivo no es el hecho de que las leyes sean creadas por los mismos ciudadanos, sino en el hecho de que ellas atiendan al bien común.

2 En este sentido, Viroli cita tres textos clásicos, que, en su opinión, constituyen el núcleo central del pensamiento republicano: «El primero es la afirmación de Tito Livio, según la cual la libertad que los romanos reconquistaron después de la expulsión de los reyes, consistía, primeramente, en el hecho de que las leyes eran más fuertes que los hombres. El segundo, el discurso relatado por Salustio, en el cual Emilio Lépido afirma que el pueblo romano es libre porque no obedece a nadie, sino a las leyes. El tercero es el paso de la Pro Cluentio de Cicerón, que dice que "somos todos esclavos de las leyes, para que seamos todos libres"» (Viroli, 1999, p. 32). 
Una apelación a Rousseau puede sucitar cierta perplejidad, ya que él es conocido como filósofo de la volonté général y de la democracia directa, como forma en la cual los individuos consiguen llegar al máximo de libertad, a través de su actividad de autogobierno. En realidad, la posición del ginebrino, es más compleja, y Viroli, que es un intérprete atento de Rousseau, señala un elemento central de esta posición: la desconfianza hacia los individuos que conforman el pueblo. Si consideramos la manera en que Rousseau concibe la participación de los ciudadanos en el proceso legislativo, debemos reconocer que ella se traduce a una simple ratificación plesbicitaria de decisiones ya tomadas por los miembros del gobierno. Los ciudadanos unidos en asamblea votan, pero nunca debaten - al contrario: Rousseau condena explícitamente todo debate, como elemento social y políticamente desagregante y desestabilizador (cf. Manin, 1987) - Menos todavía, pueden los ciudadanos hechar mano a las leyes y a las órdenes del país que, para Rousseau, poseen un caráter inviolable y casi sagrado. Por esta razón él atribuye tanta importancia al legislador: es él quien establece cuáles serán las leyes que deberán reglamentar la vida de una comunidad política.

Volvemos a Viroli y los neo-republicanos. La libertad republicana consiste, entonces, no en la mera ausencia de una interferencia arbitraria real, sino en la ausencia de cualquier interferencia arbitraria posible; y no corresponde a la autonomía legislativa de los ciudadanos, sino a la salvaguarda del gobierno de las leyes. Estos dos puntos me parecen discutibles. En primer lugar, me parece que ningún liberal, con la parcial excepción de Hobbes (por causa de su particular concepción mecanicista de la libertad), pensaría en defender una definición de libertad, entendida como simple ausencia de interferencia concreta por parte de la autoridad política o de otros sujetos. Al contrario, el liberalismo nace de la exigencia de garantizar a los individuos el respeto incondicionado para un espacio de acción y, por tanto, de garantizar el respeto incondicionado de las libertades de los individuos - libertades que son definidas de varias maneras-. Ningún liberal consideraría aceptable la situación imaginada por Pettit, o sea, aquella de un déspota benévolo, dispuesto a conceder estas libertades, reservándose, de todos modos, el derecho a violarlas cuando así le parezca. Uno de los puntos sobre los cuales todos los pensadores liberales, incluido Hobbes, siempre insistieron es, sobre todo, en la creación de un estado de seguridad jurídica: los ciudadanos deben poseer la certeza de que sus derechos son inviolables y a salvo del arbitrio del soberano. Por lo menos, desde este punto de vista, liberales y republicanos parecen compartir la misma concepción de libertad, como independencia de la dominación de otros.

La verdadera diferencia está entre la posición republicana y la radicaldemocrática. Según la lectura que de esta última hacen los neo-republicanos, la soberanía popular es ilimitada y no retrocedería ante nada, ni siquiera ante las libertades individuales. En una democracia radical, finalmente sucedería, 
justamente, lo que anteriormente fue aludido: las libertades individuales dependerían del arbitrio soberano, pero, en este caso, el soberano sería el pueblo en su totalidad. No hay contradicción entre esta visión y la definición de república, como comunidad política que se autogobierna, pues en una república el gobierno es el gobierno de las leyes que la comunidad se dio a sí misma (o que un legislador le dio en épocas remotas, como acostumbran afirmar los republicanos clásicos). La autonomía republicana, de la cual hablan los neo-republicanos, es la bartoliana, o sea, la de la ciudad que no reconoce poderes superiores y que reglamenta su vida interna con base en las leyes, cuya autoridad es garantizada por la antiguiedad de las mismas.

\section{El gobierno de las leyes}

4) Llegamos ahora al cuarto punto: la cuestión del gobierno de las leyes. Como vimos, Pettit afirma que la dominación es una interferencia arbitraria, y que la interferencia de las leyes no debe ser considerada arbitraria, contrariamente a la interferencia de la voluntad de los otros individuos (tanto déspotas, como asambleas democráticas, como lo afirma Viroli). La pregunta es: ¿por qué la interferencia de las leyes no es arbitraria? ¿Qué es lo que confiere a la ley el carácter de no-arbitrariedad? Seguramente, no el hecho de ser expresión de la voluntad de los ciudadanos, pues eso correspondería a la concepción democrática de la libertad como autogobierno y no a la republicana.

Los teóricos neo-republicanos se quedan curiosamente callados sobre este asunto. Viroli escribe: «El gobierno de la ley hace libres los individuos no porque la ley es su voluntad, si ellos dieran su consenso, sino porque la ley es un comando universal y abstracto, y por eso los protege de lo arbitrario» (Viroli, 1999, p. 37). No es claro lo que Viroli entiende aquí por «ley». Parece que él se refiere a la ley como comando universal y abstracto, independientemente de cualquier consideración sobre su contenido. Pero él critica la concepción democrática, precisamente, con base en el contenido de las leyes, pues, según él, ellas podrían privar a los individuos de su libertad y entonces él las está considerando desde el punto de vista del contenido y no de la pura forma. Lo que él debería demostrar es, entonces, o que las leyes democráticas (o sea, las leyes emanadas de una asamblea democrática a través de un proceso legislativo democrático) no son mandatos universales y abstractos, o que las leyes republicanas (independientemente de la manera en que son creadas) nunca tendrán un contenido arbitrario. Pero él no demuestra ni el primero ni el segundo punto. Él afirma, simplemente y sin dar pruebas, que las leyes republicanas nunca son arbitrarias y nunca sirven a intereses particulares. 
Claro que se podría definir «ley republicana» una ley que nunca es arbitraria y nunca sirve a intereses particulares. Entonces ella sería definida a través de su contenido y no a través de su proceso de creación. Por tanto, se podría concebir una ley republicana, creada democráticamente (y me parece que éste es justamente el tipo de ley que piensan pensadores como Madison o Maquiavelo). Además, leyes no son mandatos universales y abstractos, pero sí mandatos genéricos, cuyo destinatario no es una persona singular (en el sentido de persona jurídica), ni el interés de una persona o grupo singulares. Asimismo, muchas de ellas no pueden evitar referirse a grupos o intereses específicos. Aun cuando se suponga que ellas sean válidas en muchos casos, ellas no son universales y abstractas en el sentido que normalmente atribuimos a los dos términos. Ellas no pretenden ser aplicadas a todos los individuos en todos los tiempos (es ése el sentido en el cual hablamos, por ejemplo, de la ley moral como ley universal a la manera de Kant). Y ellas son abstractas solamente en el sentido de abstraerse de casos particulares, pues ellas tienen un contenido muy concreto: una ley de impuestos especificará cuál tipo de impuestos deben ser pagos por cuáles individuos y en qué proporción, aunque ella no especifique la suma exacta que Fulano y Mengano irán a pagar.

Las leyes son las reglas de una determinada comunidad política. Su universalismo y su abstracción son limitadas a esta comunidad, y, para ser eficaces, ellas deben especificar muy claramente quién - de sus miembroses portador de cuáles derechos y deberes; cuál tipo de comportamiento es admitido o prohibido y en cuál ocasión; cuáles son las condiciones que una transacción entre personas jurídicas debe satisfacer para tener valor legal, etc. Todo eso implica que las leyes consideren situaciones específicas, aunque no se trate de casos particulares. Para reglar eficazmente nuestras vidas, las leyes deben hacer especificaciones y, por tanto, discriminaciones (como, por ejemplo, cuando ellas prohíben relaciones sexuales entre estudiantes menores de edad y profesores, pero no entre menores de edad y adultos en general; o como cuando ellas prevén que los más ricos paguen porcentajes más elevados de impuesto a la propiedad que los más pobres).

Los mismos neo-republicanos reconocen que un cierto grado de arbitrariedad por parte de las instituciones es inevitable: «Las agencias del Estado, incluido las del Estado que promueve políticas de tipo republicano, interfieren sistemáticamente en la vida de las personas: ellas obligan a las personas en su conjunto, imponiendo a ellas leyes comunes, y obligan a individuos particulares, cuando se trata de administrar aquellas leyes y de aplicar sanciones legales» (Pettit, 1997, p. 171). Pero, los neo-republicanos se preocupan con cómo «la presencia de la voluntad arbitraria en el aparato coercitivo del Estado pueda ser minimizada» (ibid.). Ellos concentran su atención sobre la manera de evitar que «los que detentan el poder» (ibid., 173) sean manipulados o sean corrompidos o usen el poder coercitivo del Estado para 
imponer su propios intereses. Los republicanos no cuestionan la arbitrariedad de las leyes en sí, pero si la arbitrariedad de los hombres que crean las leyes. Para los republicanos, las leyes están por encima de toda sospecha, y si una ley resultase injusta, eso es por causa de la voluntad egoísta y parcial de los hombres que la crearon. Ahora, eso es verdad, pero sólo en parte, y no explica cuáles sean las condiciones en las que decimos que una ley no es arbitraria.

Decimos que una ley no es arbitraria, no porque ella no opere discriminaciones, sino porque ella no opera discriminaciones injustificadas (como en el caso de una ley que, por ejemplo, estableciera que Fulano siempre debe pagar impuestos más elevados que los otros, solamente por el hecho de ser Fulano y no por el hecho de ser más rico que los otros). Lo importante no es la manera en la cual las leyes son creadas (sea, a través de la regla de la mayoría, o por un acto arbitrario de un déspota), sino cuáles son las razones ofrecidas para su existencia. Una buena ley es una ley que tiene buenas razones para existir. Pero, ¿cuál es una buena razón? Y, sobre todo, ¿quién decide si una razón a favor o en contra de una ley es una buena o una mala razón?

\section{Gobierno de las leyes y desconfianza del pueblo}

A estas alturas, cabe hacer algunas observaciones generales. La primera es que, tras la idea del gobierno de las leyes, se encuentra siempre una cierta desconfianza contra el pueblo y sus capacidades de tomar decisiones. Se trata del miedo de que los ciudadanos, al momento de tomar decisiones, que se deberían orientar hacia el bien común, persigan, en realidad, la satisfacción de sus propios intereses personales. Esto llevaría a dos riesgos: a la creación de una situación de anarquía y fragmentación (la guerra de las opiniones de la cual Hobbes tenía tanto recelo), o al surgimiento de una verdadera dictadura de la mayoría, por lo menos, o al triunfo de un egoísmo unánime en el que, para usar la expresión de Rousseau, la volonté général se tornaría una simple volonté de tous. Aun cuando esta desconfianza pueda ser parcialmente justificada, la solución ofrecida por los neo-republicanos presenta, todavía, un grave defecto: un cierto paternalismo que puede, incluso, desembocar en una dictadura de los peritos o, para utilizar un término más moderno, en una tecnocracia. Ya que el pueblo no es capaz de decidir por sí mismo, es necesario que otros hagan eso en su lugar, por ejemplo, el gobierno que somete sus decisiones a la ratificación de la asamblea silenciosa en Rousseau, o el legislador suprahumano y omnisciente del ginebrino o de Maquiavelo, etc. Aquí emerge lo que Robert Dahl llamó el alma «aristocrática» del republicanismo, como polo contrapuesto al alma «democrática» del mismo (Dahl, 1989, pp. 27 s.). En cuanto al alma democrática, estaría ocupada en limitar las tendencias oligárquicas implícitas en cualquier tipo de gobierno popular, o sea, en la 
formación de elites políticas interesadas en disfrutar de su poder para promover intereses particulares - que no necesitan ser los intereses de ellas mismas, pero que, seguramente, no representan el interés común-, el alma aristocrática se preocuparía, por el contrario, en crear una estructura política capaz de limitar la presión de la mayoría de la popular. El espectro que se agita ante los ojos de los republicanos «aristocráticos», entre los cuales deberíamos mencionar al propio Rousseau, pero, sobre todo, a la mayoría de los Padres Fundadores norteamericanos, de Washington a John Adams, es el espectro de un gobierno dominado por las masas, de un régimen populista que ya no se ocupe del bien común. Obviamente, ni los republicanos «democráticos», ni los "aristocráticos», consiguen llegar a un acuerdo y establecer una definición unitaria de «bien común». Por tanto, este último es identificado, particularmente en el caso de los mencionados Padres Fundadores, como el interés de una determinada clase social - por ejemplo, la burguesía emprendedora o los propietarios terratenientes-, que es considerada como una especie de clase genérica en el sentido marxiano: realizar los intereses de los burgueses emprendedores o de los propietarios terratenientes significaría, entonces, realizar los intereses del país. Según los republicanos aristocráticos, el pueblo no puede tomar decisiones concretas sobre el destino del país, porque no es capaz de comprender su verdadero interés. No es por casualidad que en el debate que acompañó el proceso de creación de la nueva Constitución norteamericana, dos de los temas más discutidos fueron, justamente, la concesión del derecho de voto y la cuestión de la representatividad (cf. Schudson, 1999, pp. $48 \mathrm{ss}$.). En fin, si el pueblo (entendido como multitud, como masa de no propietarios y no emprendedores, y, por ello, como masa de artesanos, pequeños comerciantes, trabajadores, labradores, etc.) no es capaz de entender dónde está el verdadero interés del país, ¿quién puede garantizar que el pueblo sea capaz de elegir las personas justas entre aquellas que, al contrario, disponen - por definición- de la competencia necesaria? He aquí, por tanto, la inserción de limitaciones al derecho a voto, con base en los ingresos individuales. Esta medida representa, no una tentativa clasista de defensa de los propios privilegios, sino más bien refleja la convicción de que sólo quien dependa exclusivamente de sí mismo para el propio sustento, es verdaderamente capaz de decidir con imparcialidad dónde se encuentra el verdadero interés común. Al contrario, los empleados, los trabajadores y, en general, los que dependen de otros individuos, económicamente más poderosos, serían fácilmente manipulables por estos últimos y acabarían, por ende, constituyéndose en un potencial instrumento para el triunfo de los intereses particulares de los ciudadanos más ricos. Ésta es, por ejemplo, la posición de Kant, y esto demuestra una vez más, que la tradición republicana es mucho más amplia y compleja de lo que piensan los mismos neo-republicanos, al punto de que no es tan fácil diferenciarla de tradiciones alternativas, como es la liberal, de la cual Kant es habitualmente considerado un representante (Pinzani, 2003). 
Volviendo a la posición republicano-aristocrática: la desconfianza hacia el pueblo y la soberanía popular ilimitada no nacen necesariamente de un sentimiento antidemocrático, sino más bien, de la conciencia de los riesgos de revueltas populistas y, a veces, nace de una genuina preocupación por el bien común. Sólo el gobierno de las leyes sería capaz de salvaguardar la república de los peligros del populismo y de la dictadura de la mayoría, además de garantizar el triunfo del bien común.

Surgen, de todos modos, otros problemas: primeramente, aquel, ya mencionado varias veces, de definir el bien común. En muchos casos, como en aquel de los Founding Fathers, el bien común es identificado con el interés general y, este último, con los intereses de una o más de una de las clases privilegiadas. En realidad, el interés de un país en un cierto momento no coincide necesariamente con el bien común, si quisiéramos atribuir a este último concepto un sentido y un alcance que vaya más allá del simple provecho presente. Los republicanos clásicos, de Cicerón a Maquiavelo, identifican el bien común con la independencia política y con el expansionismo militar (un aspecto sobre el cual los neo-republicanos, generalmente, se quedan en silencio, pero que en el republicanismo clásico es decisivo). En todo caso, el bien común posee, para ellos, una dimensión diacrónica: no coincide, necesariamente, con el interés de los ciudadanos que viven en la república en el momento actual. Al contrario: los ciudadanos pueden ser exhortados a sacrificarse en pro del Estado y de las generaciones futuras, para que sea garantizada la independencia política de estas últimas. Rousseau es más ambiguo. En el Contrato social (II, 3) el mismo concepto de voluntad general es considerado como un concepto operacional, al punto en que el bien común resulta de un cálculo que se efectúa, eliminando «lo más o menos» de las voluntades particulares. Pero en los proyectos constitucionales para Córcega y Polonia él comparte evidentemente el ideal clásico de bien común, como independencia política de la república, a costa de los intereses individuales de los ciudadanos particulares, que son sacrificados de manera radical (como lo es en el proyecto para Córcega, en el cual, por ejemplo, los ciudadanos que dejen su ciudad para ir a vivir en otra pierden sus derechos civiles). De todos modos, no queda claro por qué la independencia política de la república debería constituir el sumo bien, para lo cual todo debe ser sacrificado. Esta independencia parece constituir un fin en sí misma, cuando las instituciones republicanas sean desvinculadas de la salvaguarda de los intereses de los individuos particulares - lo que corresponde a la renuncia del argumento más común para legitimar la existencia de instituciones en general-. Los republicanos creen que la existencia de instituciones es legitimada por el hecho de que ellas garantizan la libertad de los ciudadanos, substrayéndolos del arbitrio ajeno. La independencia del arbitrio ajeno es, por tanto, considerada un bien superior a aquel, más genérico, de la salvaguarda de los intereses particulares (más genérico porque la propia independencia puede consti- 
tuir un interés particular). Es justamente aquí, en la diversidad del criterio de legitimación de la existencia de las instituciones estatales, donde debemos buscar el verdadero elemento que diferencia liberalismo de republicanismo.

Esta diferencia de perspectivas legitimatorias explicaría también lo que llamé «paternalismo republicano». Si, como sucede en el liberalismo, ponemos en el centro de nuestra atención el interés particular, debemos reconocer que cada ciudadano es el mejor juez sobre su propio interés, ya sea este último un interés bien entendido o no. $\mathrm{Si}$, como sucede en el republicanismo, la cuestión central es la de la salvaguarda de la independencia individual, y si esta última está conectada, indisolublemente, a la independencia de la república, se vuelven decisivos los mecanismos de autodefensa de la misma república, in primis los mecanismos que garantizan la estabilidad y continuidad de sus instituciones. De ello deriva la idea de un gobierno de las leyes, en el cual ellas son sustraídas de cualquier tipo de cambios, incluyendo los cambios que podrían resultar de decisiones populares. En otras palabras, y cambiando ligeramente la perspectiva, podríamos afirmar que en el liberalismo prevalece una visión puntual, en la cual cuentan los intereses de los individuos que, en un determinado momento, son ciudadanos de un Estado. Desde este punto de vista, el mecanismo decisorio correspondiente no puede prescindir de estos intereses: por tanto, los mismos individuos deben decidir, ya que son sus propios intereses los que están en juego. En el republicanismo, por lo menos en el clásico, predomina una visión diacrónica, en la cual, lo más importante es preservar, para épocas venideras, la independencia de la república. Esta tarea debe, entonces, ser sustraída de la contingencia de los juicios de los ciudadanos, que podrían ser desviados por sus intereses momentáneos y olvidar el supremo interés del Estado. La solución es atribuir esta tarea a leyes prácticamente inmutables, una vez que la eficacia de éstas haya sido comprobada por la experiencia.

Quedaría abierta la cuestión sobre quién sería el autor de estas leyes. Ya hablé del paternalismo implícito de la concepción republicana clásica, con sus legisladores e individuos extraordinarios, encargados de crear los variados ordenamientos jurídicos. Pero, en general: ¿cómo puede prever el legislador, cuáles serán los problemas y las exigencias que la república deberá enfrentar en el futuro? En realidad, algunos teóricos republicanos, in primis Maquiavelo, creen en la posibilidad de adaptar las leyes a la situación presente, aun cuando entienden que sería una operación muy riesgosa. Otros pensadores, como Rousseau en sus dos proyectos constitucionales, ven como única solución el aislamiento de la república ante sus vecinos. El Estado debería cerrarse al exterior, estableciendo un sistema económico autárquico, en el cual el comercio es reducido a un grado mínimo, la riqueza individual es extremamente limitada y la mobilidad social es nula. En esta situación de inmobilismo y anquilosamiento, es difícil que las leyes deban ser modificadas y, por ello, será más fácil salvaguardar la independencia 
republicana. Por otro lado, la adopción de un inmobilismo de este tipo, resulta - ya en la época del mismo Rousseau—inviable en la práctica.

\section{7. ¿Qué democracia?}

Esta última constatación nos lleva a la cuestión más general de la actualidad del modelo republicano y, por ello, del neo-republicano. Más allá de la mencionada exigencia de una situación de inmobilismo social y económico, lo que suscita la mayor de las perplejidades es la caracterización de democracia que ofrecen los pensadores republicanos, actuales y pasados. Ellos tienden a dar una definición reductiva y formal, a saber: definen democracia como una forma de gobierno en la cual la voluntad popular, o sea, la voluntad de la mayoría, constituye el único criterio de elección. Evidentemente, de esta manera, el riesgo de una dictadura de la mayoría es una posibilidad siempre presente, como lo subraya Viroli, en el pasaje que cité más arriba. Pero, nuestras democracias no corresponden a esta definición.

De hecho, los neo-republicanos ofrecen una visión parcial de la historia de las tradiciones políticas. Republicanismo, liberalismo, y democracia radical no son las únicas tradiciones que ejercieron una cierta influencia sobre las sociedades democráticas contemporáneas. Dejando de lado el importante papel que el socialismo, a través de los movimientos obreros y sus conquistas sociales, tuvo sobre las social-democracias europeas, quería mencionar el papel decisivo del constitucionalismo.

Si quisiéramos atribuir a cada una de estas tradiciones un principio básico, podríamos decir que el del republicanismo consiste en la doble convicción de que la autonomía política constituiría el sumo bien, y de que ella sería realizable sólo en el ámbito de las instituciones republicanas. El principio básico del liberalismo consistiría en la creencia de que los individuos nacieron libres, de que cada uno de ellos posee el mismo valor jurídico que los otros, y que la libertad y la igualdad son inviolables. El principio básico radical-democrático afirmaría que sólo son legítimas las instituciones y normas resultantes de la voluntad popular concreta. La posición constitucionalista resulta de una reunión o amalgama de las otras, y, por ello, su principio básico afirmaría que solamente es legítimo aquel orden jurídico y aquellas instituciones que son organizadas por medio de las normas constitucionales (escritas o no) - normas, en su mayoría, sustraídas de la voluntad del propio soberano, a no ser que éste resuelva reformar la Constitución vigente o sustituirla por otra- y eso, nuevamente, no es un proceso fácil y debe ser hecho con fundamento en reglas rígidas, previamente establecidas en la misma Constitución a ser reformada.

Mezclando entre ellos, elementos de las otras tres tradiciones, el constitucionalismo llega, entonces, a una concepción, según la cual (1) el indivi- 
duo posee derechos inalienables que lo protegen del arbitrio ajeno, incluso el del Estado (ésta es una idea liberal); concepción según la cual (2) todos los individuos son autores y destinatarios del derecho al mismo tiempo (como en la tradición radical-democrática); y, según la cual, finalmente, (3) sólo son válidas las normas elaboradas con fundamento en un proceso riguroso, preciso y difícilmente modificable (concordando con la idea republicana de un gobierno de las leyes, que debe imponerse, también, contra el principio de la soberanía popular). Por eso, el constitucionalismo comparte con el liberalismo una cierta desconfianza contra el poder estatal y, en consecuencia, una gran atención a los posibles abusos de este último; el constitucionalismo comparte con la teoría radical de la democracia la idea de una participación ilimitada de los ciudadanos en el proceso legislativo, sin restricciones motivadas por pertenecer a una clase social derterminada; el constitucionalismo comparte con el republicanismo una cierta desconfianza de la multitud y contra el posible abuso del poder legislativo por parte de individuos aislados, de la mayoría o, incluso, del pueblo en su totalidad. Me parece que nuestras democracias son resultado, precisamente, de esta tradición constitucionalista, que intenta recoger un aspecto de cada una de las otras tradiciones.

A través de la Constitución, nuestras democracias garantizan a los individuos ser libres del arbitrio ajeno y del arbitrio estatal, reconociéndoles derechos inviolables e inalienables; nuestras democracias permiten a los ciudadanos que participen del proceso legislativo sin limitaciones (sin contar aquellas relativas a la edad y la salud mental) y sin caer en el paternalismo de un gobierno tecnocrático; estas democracias garantizan, finalmente, la inviolabilidad de los derechos individuales y de las instituciones ante el poder de la voluntad popular soberana. Tal vez tengan razón todos aquellos pensadores que entienden que hay incompatibilidad entre democracia y Constitución. Thomas Jefferson, por ejemplo, creía que cada 19 años, o sea, con cada nueva generación, la Constitución debía ser cambiada o escrita de nuevo, para garantizar que ella sea, verdaderamente, la expresión de la voluntad popular.

Paradójicamente, esta visión, radicalmente democrática, tiene un punto de vista común con la posición contraria a ella, a saber, la idea republicana del gobierno de leyes inmutables. En ambas perspectivas es desconocido el papel del individuo, que puede quedar indefenso ante la voluntad de la mayoría, en el primero de los casos, y, del poder estatal, en el segundo. Desde este punto de vista, una Constitución representa, al mismo tiempo, tanto una lista de reglas de juego democrático como una defensa del individuo contra la sociedad y el Estado. Los neo-liberales consideran esto como una condición necesaria para el triunfo del homo economicus y, en el fondo, del pensamiento único de un capitalismo sin frenos; personalmente, creo que esto representa, antes bien, una condición para garantizar la diversidad, la pluralidad y el 
disenso necesario para que la sociedad se mantenga viva, sin cerrarse en el inmobilismo teorizado por Rousseau. Es justamente la Constitución la que puede abrir los espacios para la crítica libre y desinhibida del sistema social y económico actual. Los avances en la lucha contra la discriminación social fueron alcanzados, más por acción del poder judicial, expresión de los valores constitucionales, que por el poder legislativo, órgano representante de la voluntad popular inmediata $-\mathrm{y}$, a veces, contra el propio poder legislativo y la voluntad de una mayoría intolerante y miedosa de la diversidad-.

De todos modos, al mismo tiempo, la Constitución, entendida como un instrumento que pertenece a las herramientas del Estado democrático nacional, en esta época pasa por una crisis de función. En un momento en el que los mayores problemas de una sociedad son provocados por factores externos a ella, como son los factores globales, la Constitución corre el riesgo de quedar vaciada de sentido. Los derechos sociales garantizados por ella - cuando tales derechos están incluidos en ella - acaban siendo amenazados, o hasta inviabilizados, por los mismos factores que hacen tambalear el Estado de Bienestar y el mismo Estado nacional. Vivimos en una época en la cual la política parece ser forzada a escoger entre: asistir impotente al triunfo de la razón económica, o tornarse una simple gestora y administradora de recursos humanos y sociales, con vistas a un desarrollo entendido exclusivamente en términos económicos. Es en estos momentos que la constitución, entendida como ánima en la vida de una sociedad, parece quedar en un plano secundario. Esto nos enfrenta a varios problemas y desafíos y nos obliga a pensar de una manera nueva los conceptos de la vida política, del orden jurídico y de la esfera pública. Ciertamente, el camino que debemos recorrer no es aquel que anunciaron los neo-republicanos, a saber, una vuelta al pasado, el Estado nacional cerrado o, incluso, el denominado «Estado ético», que impone ciertos valores y convicciones morales a los ciudadanos. El camino nos lleva, antes bien, rumbo a una internacionalización de la vida pública; nos lleva a superar los límites de las comunidades nacionales, en busca de formas de participación política a la altura de los desafíos de la globalización económica, si no queremos seguir siendo dominados por la razón económica imperante. Será un largo camino, incierto, lleno de obstáculos y errores y, tal vez, nunca lleguemos a una meta [a un fin]. Pero tenemos el compromiso de recorrerlo, recordando el dicho alemán «Der Weg ist das Ziel»: el camino es la meta.

\section{BIBLIOGRAFÍA}

ARENDT, H. (1958): The Human Condition, Chicago, Chicago University Press.

Barber, B. (1984): Strong Democracy, Participatory Politics for a New Age, Berkeley, University of California Press. 
BARON, H. (1966): The Crisis of the Early Italian Renaissance. Civic Humanism and Republican Liberty in an Age of Classicism and Tyranny, edición revisada, Princeton, Princeton University Press $\left(1 .^{\mathrm{a}}\right.$ ed.: 1955).

Bellah, R. N. (1975): The Broken Covenant. American Civil Religion in a Time of Trial, Nueva York, Seabury Press.

BERLIN, I. (1969): Four Essays on Liberty, Oxford, Oxford University Press.

BÖCKENFÖRDE E.-W. (1991): «Die Entstehung des Staates als Vorgang der Säkularisation», en id., Recht, Staat, Freiheit. Studien zur Rechtsphilosophie, Staatstheorie und Verfassungsgerschichte, pp. 92-114, Frankfurt a. M., Suhrkamp.

CONSTANT, B. (1819): De la liberté des anciens comparée à celle des modernes, Paris.

DAGGER, R. (1997): Civic Virtues. Rights, Citizenship, and Republican Liberalism, Oxford, Oxford University Press.

DAHL, R. (1989): Democracy and Its Critics, New Haven/Londres, Yale University Press.

DieTz, M. (1990): «Hobbes's Subject as Citizen», en Thomas Hobbes and Political Theory, DiETZ, M. (ed.), pp. 91-119, Lawrence, University Press of Kansas.

Galston, W. (1991): Liberal Purposes. Goods, Virtues, and Diversity in the Liberal State, Cambridge, Cambridge University Press.

Holmes, S. (1993): The Anatomy of Antiliberalism, Cambridge (MA)/Londres, Harvard University Press.

HonOHAN, I. (2002): Civic Republicanism, Londres/Nueva York, Routledge.

MACEDO, S. (1990): Liberal Virtues. Citizenship, Virtue and Community in Liberal Constitutionalism, Oxford, Clarendon Press.

- (1992): «Charting Liberal Virtues», en Virtue. Nomos XXXIV, J. W. ChapMAN y W. A. Galston (eds.), pp. 204-232, Nueva York/Londres, New York Universiy Press.

ManIN, B. (1987): «On Legitimacy and Political Deliberation», Political Theory, núm. 13 (5), pp. 338-368.

PETTIT, P. (1997): Republicanism. A Theory of Freedom and Government, Oxford, Oxford University Press.

PINZANI, A. (2003): «Il cittadino in Kant tra liberalismo e repubblicanesimo», Filosofia politica, núm. 1, 2003, pp. 109-126.

- (2004): «Patrioti o diavoli? Identità collettiva, sovranità nazionale e libertà individuali tra (neo-) repubblicanesimo e liberalismo», Fenomenologia e società, núm. 27 (1), pp. 68-100.

Pocock, J. G. A. (1975): The Machiavellian Moment. Florentine Political Thought and the Atlantic Republican Tradition, Princeton, Princeton University Press.

RAwLS, J. (1971): A Theory of Justice, Cambridge (MA), Bellknap.

- 1993: Political Liberalism, Nueva York, Columbia University Press.

RIKLIN, A. (1999): Ambrogio Lorenzettis politische Summe, Bern, Stämpfli.

RousSEAU, J.-J. (1996): El contrato social, Barcelona, Altaya.

SARAMAGO, J. (2004): Ensayo sobre la lucidez, Madrid, Alfaguara.

Schudson, M. (1999): The Good Citizen. A History of American Civic Life, Cambridge (MA)/Londres, Harvard University Press.

SKINNER, Q. (1998): Liberty before Liberalism, Cambridge, Cambridge University Press.

SKINNER, Q., y VAN GELDEREN, M. (eds.): (2002): Republicanism: A Shared European Heritage, 2 vols., Cambridge, Cambridge University Press. 
STRauss, D. A. (1992): «The Liberal Virtues», en Virtue. Nomos XXXIV, J. W. Chapman y W. A. Galston (eds.), pp. 197-203, Nueva York/Londres, New York Universiy Press.

VIROLI, M. (1999): Repubblicanesimo, Roma/Bari, Laterza.

WALZER, M. (1996): Zivile Gesellschaft und amerikanische Demokratie, Frankfurt a. M., Fischer. 